\title{
Recycling of 3D Printable Thermoplastic Cellulose-Composite
}

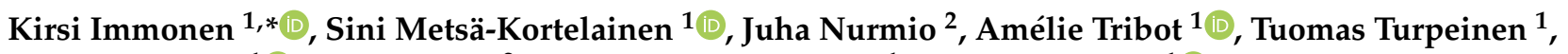 \\ Atte Mikkelson ${ }^{1}{ }^{\mathbb{D}}$, Tomi Kalpio ${ }^{2}$, Otto-Ville Kaukoniemi ${ }^{1}$ and Heli Kangas ${ }^{1} \mathbb{D}$ \\ 1 VTT Technical Research Centre of Finland Ltd., FI-02044 Espoo, Finland; \\ sini.metsa-kortelainen@vtt.fi (S.M.-K.); amelie.tribot@vtt.fi (A.T.); tuomas.turpeinen@vtt.fi (T.T.); \\ atte.mikkelson@vtt.fi (A.M.); otto-ville.kaukoniemi@vtt.fi (O.-V.K.); heli.kangas@vtt.fi (H.K.) \\ 2 Brinter Oy, FI-20520 Turku, Finland; juha@brinter.com (J.N.); tomi.kalpio@brinter.com (T.K.) \\ * Correspondence: kirsi.immonen@vtt.fi; Tel.: +358-405185351
}

Citation: Immonen, K.; Metsä-Kortelainen, S.; Nurmio, J.; Tribot, A.; Turpeinen, T.; Mikkelson, A.; Kalpio, T.; Kaukoniemi, O.-V.; Kangas, H. Recycling of 3D Printable Thermoplastic Cellulose-Composite. Sustainability 2022, 14, 2734. https:// doi.org/10.3390/su14052734

Academic Editor: Graeme Moad

Received: 28 December 2021

Accepted: 23 February 2022

Published: 25 February 2022

Publisher's Note: MDPI stays neutral with regard to jurisdictional claims in published maps and institutional affiliations.

Copyright: (c) 2022 by the authors. Licensee MDPI, Basel, Switzerland. This article is an open access article distributed under the terms and conditions of the Creative Commons Attribution (CC BY) license (https:/ / creativecommons.org/licenses/by/ $4.0 /)$.

\begin{abstract}
D printing enables sustainable product innovations through novel design, reduced use of materials, and local manufacturing. Sustainable 3D printing can further be realized using recyclable materials. Cellulose is an abundantly available renewable material. Modified celluloses, such as thermoplastic cellulose esters, are widely used in injection molding applications. The aim of this research was to study the properties of a cellulose-based composite (cellulose acetate propionate (CAP) polymer matrix with $20 \mathrm{wt}$ \% microcellulose) in injection molding and granular extrusionbased 3D printing processes over multiple recycles. The impact of the processing methods on the composite's properties were investigated. Both injection molded and 3D printed samples were ground with plastic grinding mill to particle sizes below $3 \mathrm{~mm}$ after each preparation stage and reused as such in the next process cycle. Morphology, mechanical and thermal properties, and material degradation were analyzed. The thermoplastic cellulose-based compound was found to be directly recyclable for both processes without the need for any additional compounding steps. The polymer matrix was able to withstand at least seven processing cycles without degradation. However, microcellulose was found to be more sensitive to thermal stress. The mechanical and thermal properties of the cellulose-based composites remained close to initial levels throughout.
\end{abstract}

Keywords: 3D printing; cellulose; recycling; thermoplastic; cellulose-composite; cellulose acetate propionate; granulate printing; injection molding

\section{Introduction}

3D printing has been increasingly used for the manufacturing of production parts (49\%) and spare parts $(32 \%)$, as well as for the rapid fabrication of prototypes $(68 \%)$ and proof of concepts (59\%) in automotive, aerospace, manufacturing industry, medical, electronics, construction, and consumer goods [1]. The global, 3D printing market was $\$ 15.8$ billion in 2020 and is expected to reach $\$ 56.1$ billion by 2026. 3D printing materials accounted for a market share of approximately $12 \%$ for which $27 \%$ was attributable to thermoplastic materials. Thermoplastic materials represented the second-largest segment of 3D printing materials after photopolymers in 2020 [2].

The benefits of 3D printing include design flexibility and swift manufacturing of complex shapes and customized parts without the need for any special tools or molds. Sustainability is a feature of 3D printing as it enables on-demand and local manufacturing, reduced time to market and shorter supply chains. 3D printed parts are usually highly optimized and lightweight with positive consequences on the environmental impact in a product life cycle perspective [3]. One of the key elements related to the sustainability of $3 \mathrm{D}$ printing is the reduced use of materials and waste generation during the manufacturing process.

Sustainable development is also driving advances in materials for 3D printing technologies. The most highly used thermoplastic materials in fused filament/granular fabrication 
are acrylonitrile butadiene styrene (ABS) and polylactic acid (PLA), for which increasing amounts are being derived from recycled materials [4]. Aside from conventional 3D printing materials, novel bio- or cellulose-based polymers and composite materials have been introduced $[5,6]$. Sustainable extraction of raw materials, preferably from renewable sources, is essential from the circular economy point of view. Moreover, every stage, from material processing, product design, manufacturing, to use and post-use, needs to be considered when assessing sustainability in order to realize minimal energy consumption, reduced processing steps and lower waste generation. At end-of-life, product remanufacturing, reuse or recycling are the available options from the closed-loop perspective. Sustainable manufacturing follows the $6 \mathrm{R}$ principles (reduce, remanufacture, reuse, recover, recycle, and redesign) [7].

Materials' recyclability after the product's end-of-life is critical from the environmental sustainability point of view, especially when lifetimes of products are short, e.g., in the manufacturing of prototypes or molds. In addition, straightforward and energy efficient recycling processes are preferred. The Association of Plastic Recyclers recently published a study on the life cycle impacts of recycled polyethylene terephthalate (PET), high density polyethylene (HDPE) and polypropylene (PP), and determined that using recycled plastic, it was possible to reduce total energy consumption by $79 \%$ for PET, $88 \%$ for HDPE and $8 \%$ for PP. The use of recycled plastics also reduced emissions by $67 \%$ for PET, $71 \%$ for HDPE and $71 \%$ for PP [8].

Very few studies exist on the recyclability of 3D printed thermoplastic objects, and of those that are available, most focus on the recycling phases of thermoplastic materials and comparison of properties and quality of specimens made from virgin and recycled feedstock materials [9]. Cress et al. studied the performance of 3D printed specimens made from ABS after three recycling rounds. Between rounds, the specimens were mechanically granulated, and filament was also prepared from the granules. Recycling increased the porosity of the 3D printed specimens and decreased the tensile strength and strain at break by 10 and $25 \%$, respectively [10]. Vidakis et al. studied the properties of glycol-modified polyethylene terephthalate (PETG), polyamide 12 (PA12) and PP using 3D printing and filaments made from virgin material (first round), recycled, or crushed filaments (granules) over multiple cycles. The results varied among the materials showing slight increase of mechanical properties after the first recycling round and ultimately leading to issues in material flow during the 3D printing process after the fifth round with PETG and PA12 [11-13]. Spoerk et al. investigated the effect of heat stabilizers added in PP composites for 3D printing and observed that the morphology, viscosity, and mechanical properties remained unchanged after 15 extrusion (recycling) cycles with the composite containing heat stabilizers [14]. Cruz Sanchez studied the recycling of PLA filaments in additive manufacturing and measured a decrease in tensile strength properties already after the first recycling cycle [15].

PLA-based lignocellulosic fiber composites are one of the main thermoplastic composite materials based on renewable raw materials used in 3D printing. The recycling of PLA-bamboo fiber, PLA-Sisal fiber and PLA wood cellulose fiber composites was studied, and the findings showed a tensile strength reduction for all of these materials after recycling. The tensile strength reduction was found to be mainly related to PLA degradation [16-18].

Cellulose esters, such as cellulose acetate butyrate or cellulose acetate propionate (CAP), are a class of materials based on an abundantly available renewable material, cellulose, and have been used for decades in injection molding to manufacture for example, tool handles, eyeglass frames and transparent decorative items [19]. These materials are already mechanically recycled at the industrial scale and in China they already have their own material codes [20-22]. Mohanty et al. found that processing parameters played a vital role in designing cellulosic plastics with the desired properties for bio-composite applications [23].

The thermoplastic cellulose-based composite material for 3D printing used in this study was introduced earlier by the authors [24]. In this work, the recyclability of the 
thermoplastic cellulose-based composite material consisting of microcellulose (MC) fiber, renewable cellulose ester polymer (CAP) and cellulose palmitate was studied. The aim was to evaluate the effect on the composite material of recycling through an injection molding manufacturing process and a 3D printing process using a granular printing method. The differences in material properties related to the different manufacturing methods were also analyzed.

\section{Materials and Methods}

\subsection{Materials}

The polymer matrix used for the preparation of the cellulose-based compound was cellulose acetate propionate (CAP) (CELLIDOR CP300-13, Albis Plastics GmbH, Hamburg, Germany) with a phthalate free plasticizer content of $13 \%$ and a melt flow rate of $7.5 \mathrm{~cm}^{3} / 10 \mathrm{~min}\left(210^{\circ} \mathrm{C}, 2.16 \mathrm{~kg}\right)$ [25]. The cellulose fiber used in the compounds in the amount of $20 \mathrm{wt}$. \% was microcrystalline cellulose (VIVAPUR 105, JRS Pharma GmbH, Weissenborn, Germany) with an average particle size based on laser diffraction of $15 \mu \mathrm{m}$. In the coupling of fiber and polymer, a reactive epoxidized linseed oil was used (Lankroflex ${ }^{\mathrm{TM}}$ L, Valtris Specialty Chemicals, Independence, $\mathrm{OH}$, USA). As an additional plasticizer in the compound at an amount of $4 \mathrm{wt}$. \%, a thermoplastic cellulose ester prepared at VTT according to the method described by Willberg-Keyriläinen et al. [26] was used. There palmitic acid (C16) is used for cellulose esterification.

\subsection{Processing}

A larger batch of granules $(25 \mathrm{~kg})$ was prepared by compounding material for recycling tests in both injection molding and 3D printing. Test specimens were initially produced from native material using both manufacturing methods. Specimens were then analyzed and reprocessed (recycled) back to raw material for further manufacturing rounds by grinding with a Rapid 150 granulator (Rapid Granulator AB, Bredaryd, Sweden) against a 3 mm size holes in the sieve. The ground material with particle size below $3 \mathrm{~mm}$ and scrappy structure was used as is in both further injection molding and granular 3D printing processes.

In the results section, the number one (1) refers to the first injection molding or 3D printing process round with native material, number two (2) is the first recycled material process round and so forth. The material was recycled a total of seven times with respect to injection molding processing and four times in $3 \mathrm{D}$ printing processing.

\subsubsection{Compounding and Injection Molding}

MC fibers were treated with the Lankroflex L coupling agent before compounding by mixing $5 \%$ of Lankroflex $\mathrm{L}$ in relation to $\mathrm{MC}$ dry weight using a blade blender. The mixture was dried overnight in a heat convection oven at $50{ }^{\circ} \mathrm{C}$. The thermoplastic cellulose additive $\mathrm{C} 16$ was also dried at $50{ }^{\circ} \mathrm{C}$ overnight before compounding. The polymer matrix $\mathrm{CAP}$ was dried at $80{ }^{\circ} \mathrm{C}$ for $2 \mathrm{~h}$.

21 wt. \% of additive (Lankroflex L) containing MC and 4 wt \% C16 were compounded with CAP using a co-rotating twin-screw extruder (Berstorff ZE 25x33 D, Berstorff GmbH, Hanover, Germany). The extruder zone temperatures ranged from 80 to $205^{\circ} \mathrm{C}$, the speed was $100 \mathrm{rpm}$ and the output was $2 \mathrm{~kg} / \mathrm{h}$. The small granules produced from compounding were used for both injection molding and 3D printing (see Section 2.2.1.1) processing.

Injection molding of granules was carried out with an injection molding machine (Engel ES 200/50 HL, Engel Maschinenbau Geschellschaft m.b.H, Schwefberg, Austria) to test specimens according to ISO 527. The processing temperatures during injection molding varied from 180 to $200{ }^{\circ} \mathrm{C}$ in the screw, $200{ }^{\circ} \mathrm{C}$ in the nozzle, and the mold temperature was $70^{\circ} \mathrm{C}$.

\subsubsection{3D Printing}

3D printing of granules was performed with the Brinter Granu Tool (BRINTER ${ }^{\circledR} 1$, Turku, Finland) presented in Figure 1 (left). The printing with the Granu Tool is based 
on the hot extrusion method. The thermoplastic granular material is melted inside an extrusion barrel and pushed toward the nozzle by a rotating screw. The extrusion barrel and the nozzle can be heated up to $+250{ }^{\circ} \mathrm{C}$.

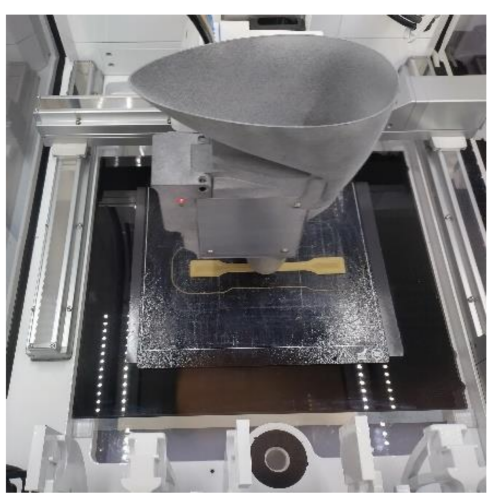

(a)

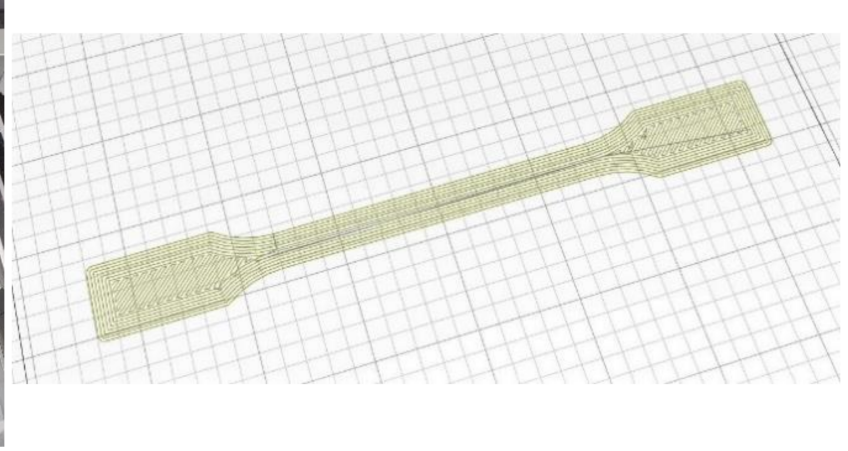

(b)

Figure 1. Granular 3D-printer from Brinter (a) and printing pattern used in recycling test (b).

The processing temperature during 3D printing was $215^{\circ} \mathrm{C}$, the temperature of the printing bed was $60^{\circ} \mathrm{C}$, and the other parameters are shown in Table 1 . The minimum 30 test bars according to ISO 527 were printed using the pattern presented in Figure 1 (right). The printing was done on a glass plate covered with a magnetic sheet coated with a FYSETC-steel plate. A thin film of ABS-acetone solution was spread on the printing plate to improve the adhesion of the thermoplastic material.

Table 1. Processing parameters used in 3D printing.

\begin{tabular}{cc}
\hline Parameter & Value \\
\hline Nozzle diameter, $\mathrm{mm}$ & 0.8 \\
215 \\
Printing temperature, ${ }^{\circ} \mathrm{C}$ & 1st layer 0.8 , other layers 0.8 in the 1st and 2nd prints, 0.5 in the \\
3rd, 4 th and 5 th prints \\
Layer height, $\mathrm{mm}$ & 5 in the 1st and 2nd prints, 7 in the 3rd, 4 th and 5 th prints \\
& solid infill (angle $\left.45^{\circ}\right)$, overlap 0.33 \\
Shell count & $1.1 \times$ \\
Extrusion factor & -0.2 \\
Z offset, $\mathrm{mm}$ & \\
\hline
\end{tabular}

\subsection{Analytics and Testing}

\subsubsection{Scanning Electron Microscopy (SEM)}

Sample morphologies were studied using a Scanning Electron Microscope (SEM) from a cross-cut sections of the test bars. Images were taken from the fractured surfaces of samples used in impact strength tests. The sample surfaces were coated with gold to prevent surface charging. The gold film thickness was 50-70 nm. Analyses were performed using a scanning electron microscope JEOL JSM T100 (JEOL Ltd., Tokyo, Japan) with a voltage of $10 \mathrm{kV}$.

\subsubsection{Microtomography}

The cross-sectional structures of the samples were studied using microtomography $(\mathrm{X} \mu \mathrm{CT})$. The $\mathrm{X} \mu \mathrm{CT}$ reconstructions were obtained using an RX-Solutions Desktom 130 $\mathrm{X} \mu \mathrm{CT}$ scanner (Chavanod, France). The main scanning parameters were the following: $50 \mathrm{keV}$ acceleration voltage (4 W power), $1 \mathrm{~s}$ exposure time, average of four images per shadowgram and a total of 1440 images in each rotation series. The images were scanned from the middle cross sections of the dog-bone shaped test bars in the $x-y$-direction. 


\subsubsection{Mechanical Testing}

Tensile tests were performed according to the ISO-527 standard using an Instron 4505 Universal Tensile Tester (Instron Corp., Canton, MA, USA) and an Instron 2665 Series High Resolution Digital Automatic Extensometer (Instron Corp., Canton, MA, USA) with a $10 \mathrm{kN}$ load cell and a $5 \mathrm{~mm} / \mathrm{min}$ crosshead speed. Five parallel specimens were tested for each sample material to obtain average values of the tensile properties.

Impact strengths were determined according to the ISO-179 standard using a Charpy Ceast Resil 5.5 Impact Strength Machine (CEAST S.p.a., Turin, Italy). Charpy impact strength tests in edgewise orientation were carried out on unnotched specimens. Impact testing was done on six to ten replicates to obtain an average value and variance.

Test specimens were kept in standard conditions $\left(23{ }^{\circ} \mathrm{C}, 50 \%\right.$ relative humidity) for at least five days before testing.

\subsubsection{Melt Flow Index (MFI)}

MFIs of the material compounds were analyzed using a RAY-RAN Melt Flow Indexer, Model 3A (Industrial Physics, Theme, UK). Tests were performed at a temperature of $210^{\circ} \mathrm{C}$ under a weight of $2.16 \mathrm{~kg}$ of weight with four parallel samples.

\subsubsection{Heat Distortion Temperature (HDT)}

HDTs was measured according to the ISO-75 standard using method A with $1.8 \mathrm{MPa}$ stress on the samples. HDTs were determined using the Ceast HDT 3 VICAT P/N 6911.000 (Ceast S.p.a., Turin, Italy) system with three parallel samples.

\subsubsection{Molar Mass}

Molar mass was determined with size exclusion chromatography (SEC) using a chloroform (Sigma Aldrich purity $\geq 99.8 \%$ ) eluent. The samples were ground using a Wiley Mill model 3 (Arthur H. Thomas Co., Philadelphia, PA, USA) before dissolving in chloroform overnight at $5 \mathrm{mg} / \mathrm{mL}$ concentration. In all cases, the samples were filtered $(0.45 \mu \mathrm{m})$ before measurement.

The SEC measurements were performed in a chloroform eluent (with a flow rate of $0.6 \mathrm{~mL} / \mathrm{min}$ and temperature of $30^{\circ} \mathrm{C}$ ) using Styragel HR 4 and 3 columns with a pre-column. The elution curves were measured using a Waters 2414 Refractive index detector (Waters Corporation, Milford, CT, USA). The molar mass distributions (MMD) were calculated against $8 \times$ PS $(1260-1,030,000 \mathrm{~g} / \mathrm{mol})$ standards, using Waters Empower 3 software.

\subsubsection{Fiber Dimensions}

Fiber lengths were analyzed from the injection molded samples by dissolving the polymers with Soxhlet-extraction. A small number of composite samples were placed into the Soxhlet thimble and fluxed with a hot solution of chloroform for a minimum of $72 \mathrm{~h}$. After the fibrous material was extracted from the polymer matrix, it was dispersed in ethanol and the particle sizes of the fibers were analyzed using a particle size analyzer (Malvern Mastersizer 3000, Malvern Instruments ltd., Worcestershire, UK). The particle size analyzer was used instead of a fiber analyzer due to microcellulose being more particle-like than fibrous.

\section{Results}

\subsection{Visual Inspection}

3.1.1. Pictures of the Samples

Photographs of the samples are presented in Figure 2 with the number of recycling rounds increasing from left to right. A gradual color change or darkening of the samples with recycling can be observed. This change is related to increased thermal stress effects on the microcellulose fibers. In a previous paper by the authors, the degradation of this material compound was found to intensively occur after a temperature of $277^{\circ} \mathrm{C}$ was 
reached (TGA result for 5\% degradation), but some degradation has already taken place at lower temperatures [24]. Typically, hemicellulose residues in microcellulose start to degrade already at $200{ }^{\circ} \mathrm{C}$ [27].

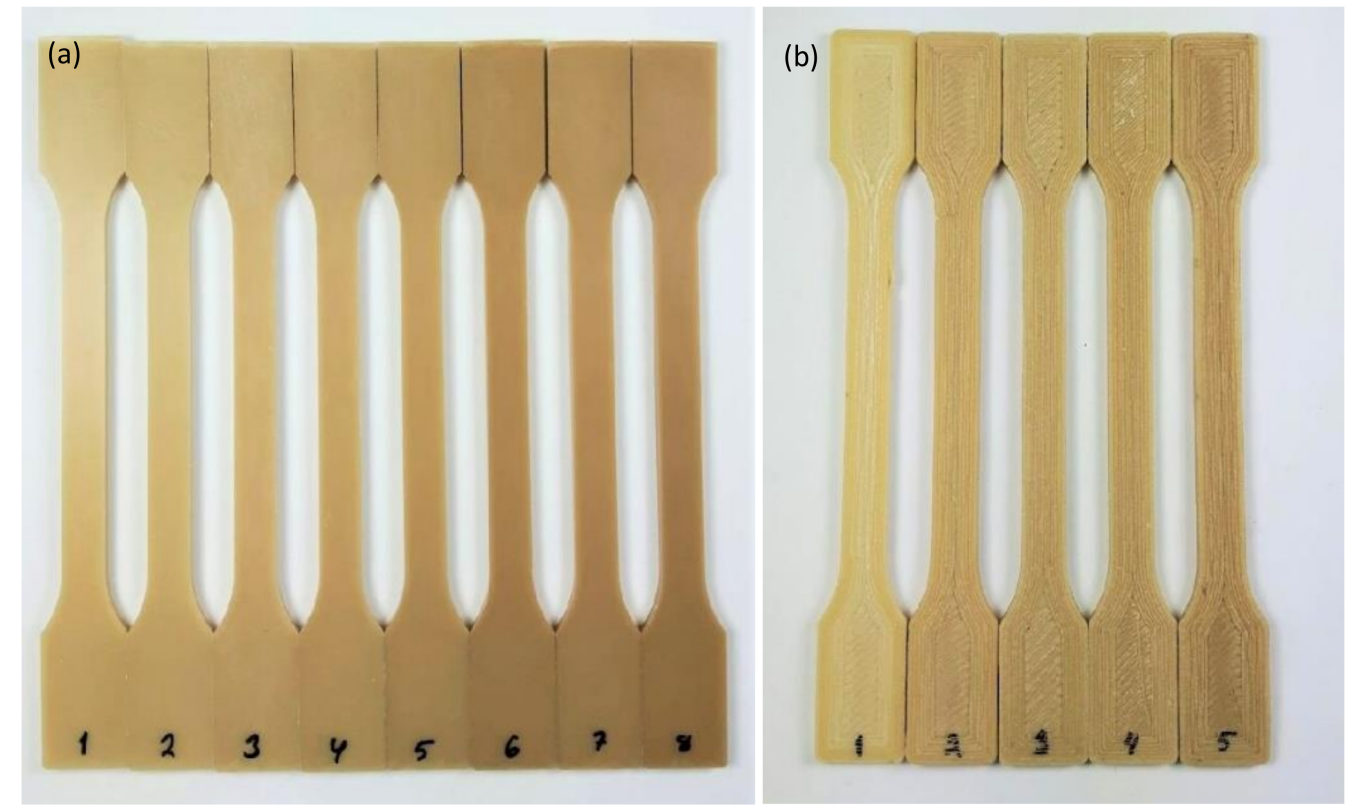

Figure 2. Photographs of recycled injection molded (a) and 3D printed (b) material samples. The number of recycling rounds increases from left to right.

\subsubsection{SEM}

The morphology study for the injection molded and 3D printed materials was made using SEM. SEM-micrographs of injection molded samples 1-IM, 5-IM and 8-IM are presented in Figure 3 and of 3D printed samples 1-3D and 5-3D in Figure 4. Slightly increased homogeneity, i.e., better coupling between fiber and polymer matrix, and smaller particle sizes are indicated in Figure 3 for the injection molded samples with increased amount of recycling rounds.

As the micrographs are taken from cross sections of the sample surfaces from the impact strength tests, empty spaces where the fibers have been severed from the polymer matrix can also be seen. White arrows show some fibers still pointing out from polymer. In addition to smaller sizes with increasing recycling rounds, there is also indication of breakage of fiber agglomerates. In the 3D printed samples (see Figure 4), as opposed to the injection molded samples, the fibers stay quite large even after four recycling rounds (5-3D). This consistency is due to the lower pressure and shear forces focused on the fibers during 3D-printing than during injection molding as explained in more details in the discussion. Enhanced fusion of the printed layers and a decrease in void size was also observed and validated by microtomography.

\subsubsection{Microtomography}

Microtomography scanning of the injection molded (1-IM and 8-IM), and 3D printed (1-3D and 5-3D) samples was done after rounds 1 and 8 , and rounds 1 and 5, respectively. The resulting images are presented in Figure 5. These images track the evolution of the microcellulose fibers (lighter gray areas) and their agglomerates after multiple recycling rounds. The fibers are clearly visible in the injection molded samples showing the ensuing reduction in fiber size and improved fiber dispersion inside the material after seven recycling rounds. The effect of recycling on 3D printed material is observed as reduced porosity and improved layer adhesion between printed layers and adjacent printing paths, which is related to the higher flowability of the material after several recycling rounds 
and established by the MFI results shown in Section 3.2.1. The improved layer adhesion and reduced porosity also reflects an enhancement of strength properties and is explained further in the discussion section.

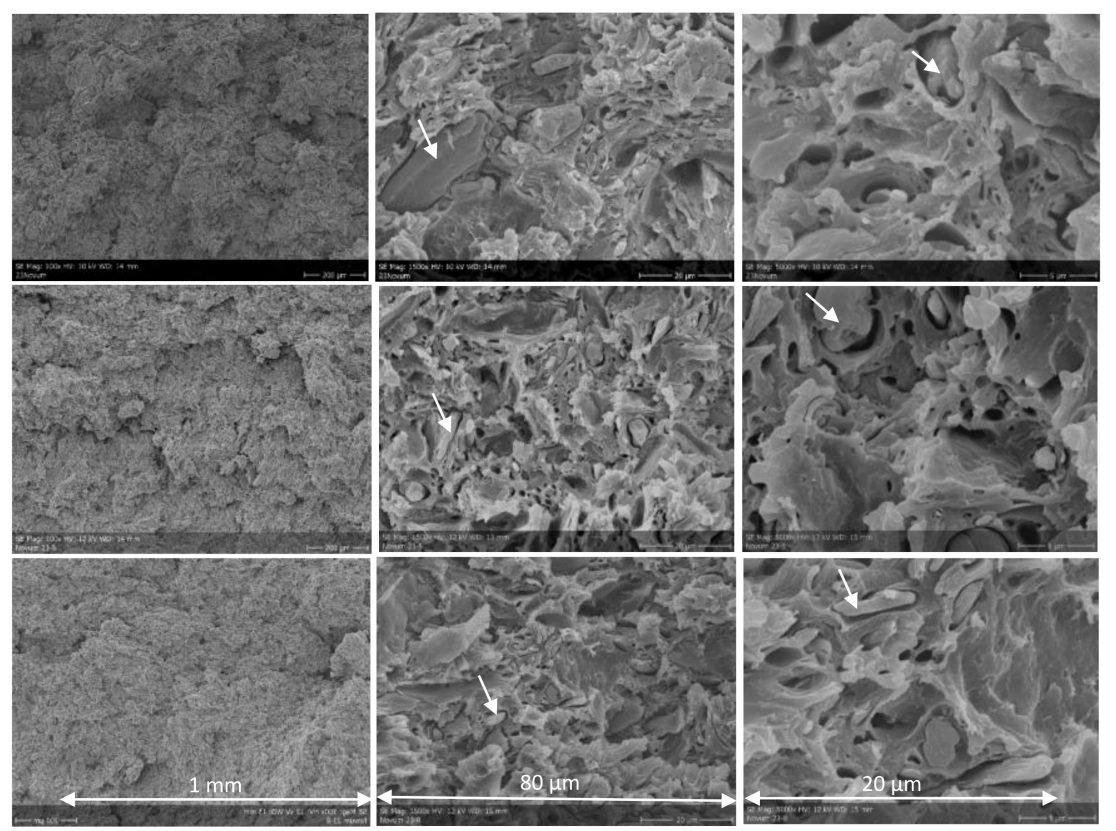

Figure 3. SEM-micrographs of the injection molded samples 1-IM (1st row), 5-IM (2nd row) and 8-IM (3rd row) with magnifications of $100 \times$ (left 1 st column), $1500 \times(2$ nd column) and $5000 \times$ (right 3 rd column). Arrows point to microcellulose particles inside the polymer matrix.

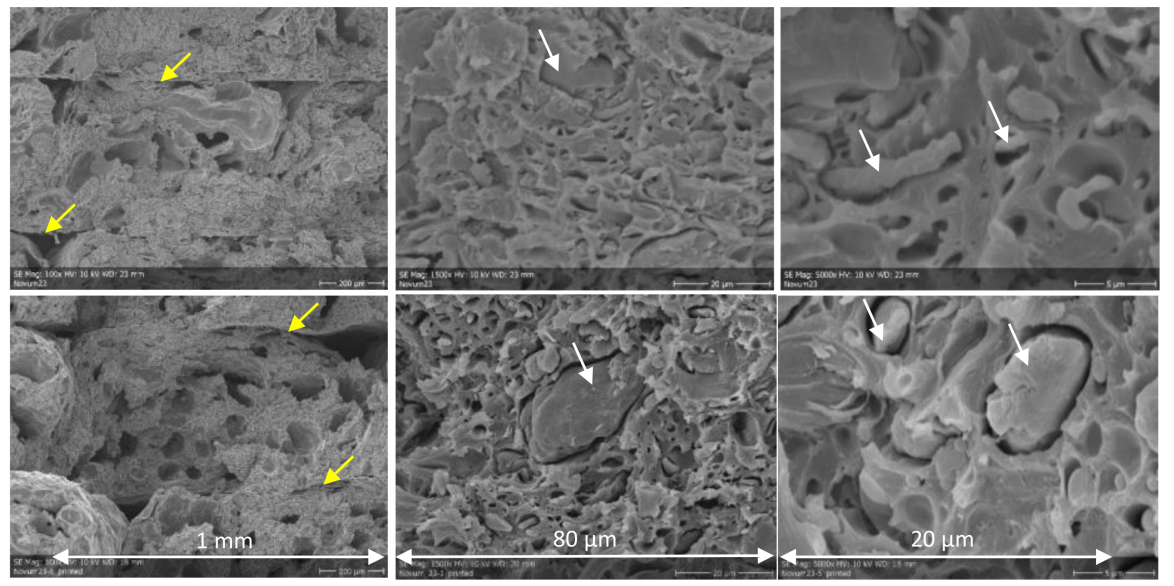

Figure 4. SEM-micrographs of the 3D printed samples 1-3D (1st row) and 5-3D (2nd row) with magnifications of $100 \times$ (left 1 st column), $1500 \times(2$ nd column) and $5000 \times$ (right 3 rd column). White arrows indicate microcellulose particles inside the polymer matrix and yellow arrows in the left column indicate the location of layer-to-layer spacing.

\subsection{Fiber and Polymer Analytics}

\subsubsection{MFI}

MFI was analyzed at $210{ }^{\circ} \mathrm{C}$ for both injection molding and 3D printing materials, before processing and after recycling. The results are presented in Figure 6 and show clear increases in material flowability with recycling after thresholds of two (injection molded sample 3-IM) and one (3D printed sample 2-3D) recycles. 

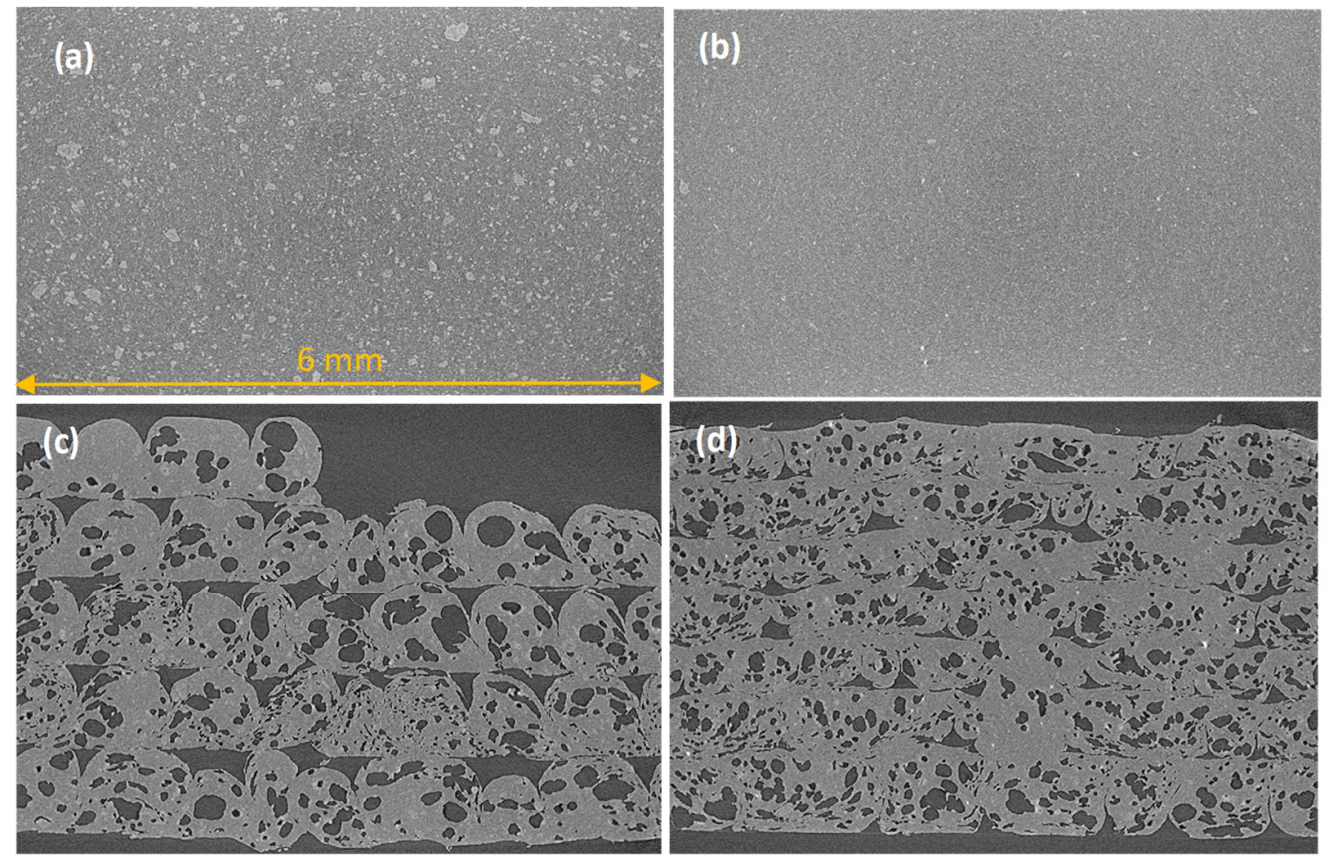

Figure 5. Microtomography images of samples 1-IM (a top left), 8-IM (b), 1-3D (c) and 5-3D (d).

\subsubsection{SEC Results}

Weight average molar mass $\left(M_{w}\right)$, number average molar mass $\left(M_{n}\right)$ and dispersity $(\nexists)$ were determined for the polymer matrixes extracted from both injection molded and 3D printed samples using SEC. The results are presented in Table 2 and show that the $M_{w}$ stays at the same level of 205,000 $\pm 8000 \mathrm{~g} / \mathrm{mol}$ for both injection molded and 3D printed samples, and does not demonstrate any obvious effect due to recycling. These results confirm that the polymer matrix is not degraded with recycling. However, there are significant differences in $M_{n}$ and $Ð$ between the injection molded and 3D printed samples. $M_{n}$ is the average molar mass of individual molecules, thus the number of different chain lengths has higher significance than in $M_{w}$, giving more weight to the smaller molecules. The chromatographs in Figure 7 reveal smaller molecules in the 3D printed polymer matrix than in the injection molded polymer, which is reflected by the higher $Ð$ of $2.8-2.9$ for the former compared to 1.9-2.3 $Đ$ for the latter. One explanation is that the reactive, epoxymodified linseed oil additive acted more efficiently as a coupling agent between polymer chains during injection molding due to the higher processing pressures and shear forces than used in 3D printing, which reduces the number of smaller molecules during injection molding. Moreover, the MFIs presented in Section 3.2.1 confirm the higher flow properties of materials recycled via the $3 \mathrm{D}$ printing route, which also indicates the presence of shorter polymer chains. 


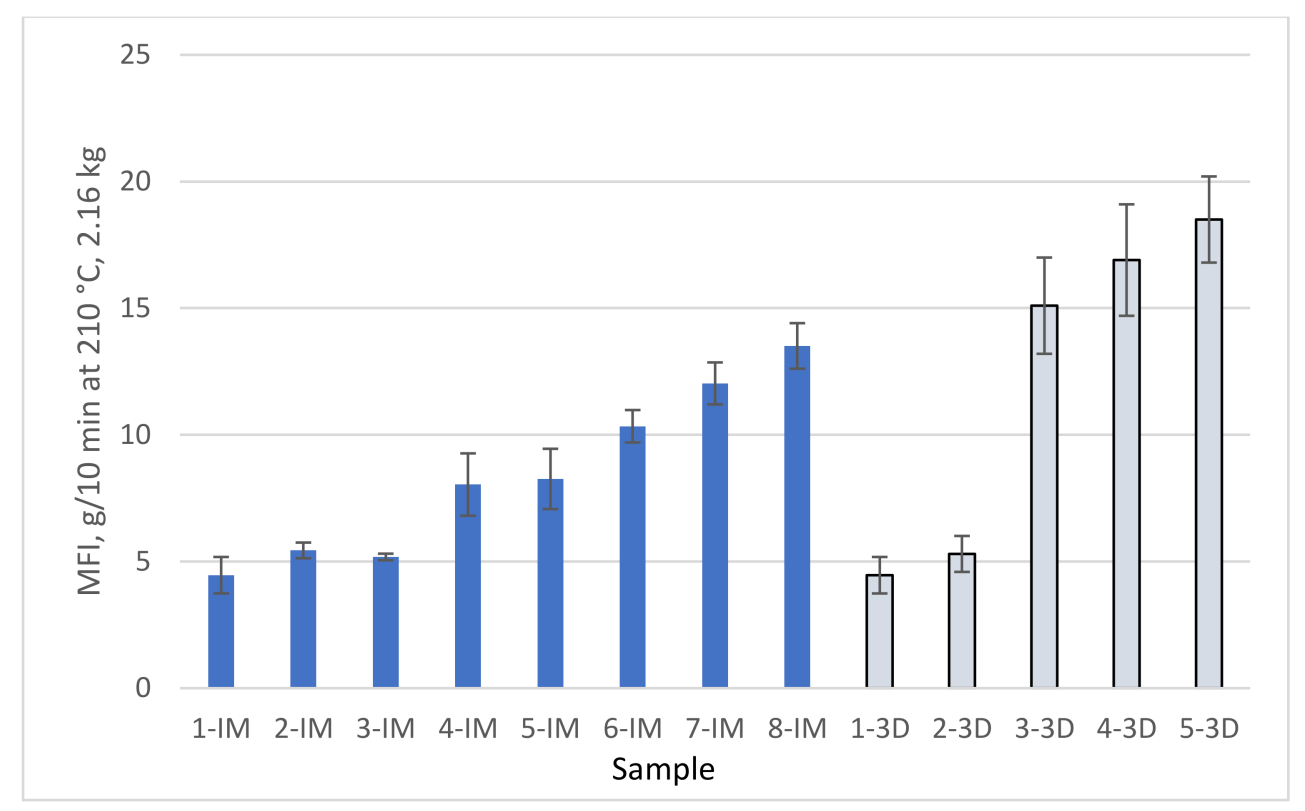

Figure 6. MFI at $210{ }^{\circ} \mathrm{C}(2.16 \mathrm{~kg})$ for the injection molded and 3D printed samples.

Table 2. SEC results for weight average molar mass $\left(M_{w}\right)$, number average molar mass $\left(M_{n}\right)$ and dispersity $(\bigoplus)$.

\begin{tabular}{cccc}
\hline Sample & $\boldsymbol{M}_{\boldsymbol{w}}, \mathbf{g} / \mathbf{m o l}$ & $\boldsymbol{M}_{\boldsymbol{n}}, \mathbf{1} / \mathbf{m o l}$ & $\boldsymbol{\Xi}, \mathbf{-}$ \\
\hline 1-IM & 202,847 & 88,357 & 2.3 \\
2-IM & 218,305 & 109,073 & 2.0 \\
3-IM & 198,606 & 86,907 & 2.3 \\
4-IM & 206,036 & 88,598 & 2.3 \\
5-IM & 206,135 & 91,882 & 2.2 \\
6-IM & 200,255 & 88,358 & 2.3 \\
7-IM & 205,681 & 92,140 & 2.2 \\
8-IM & 201,793 & 105,244 & 1.9 \\
1-3D & 197,465 & 70,661 & 2.8 \\
2-3D & 207,438 & 72,810 & 2.8 \\
3-3D & 211,971 & 75,976 & 2.8 \\
4-3D & 205,726 & 71,334 & 2.9 \\
5-3D & 211,750 & 74,269 & 2.9 \\
\hline
\end{tabular}

\subsubsection{Particle Size}

Results for the particle size analysis of microcellulose fibers separated from injection molded and 3D printed samples are presented in Table 3. The analyzed samples were IM-1, IM-8, and 3D-5, meaning the first and last injection molded samples and the last 3D printed sample. The results show that the particle size distribution of microcellulose shifts to smaller size fractions due to recycling and that the injection molding process is more effective in reducing particle size than 3D-printing. 

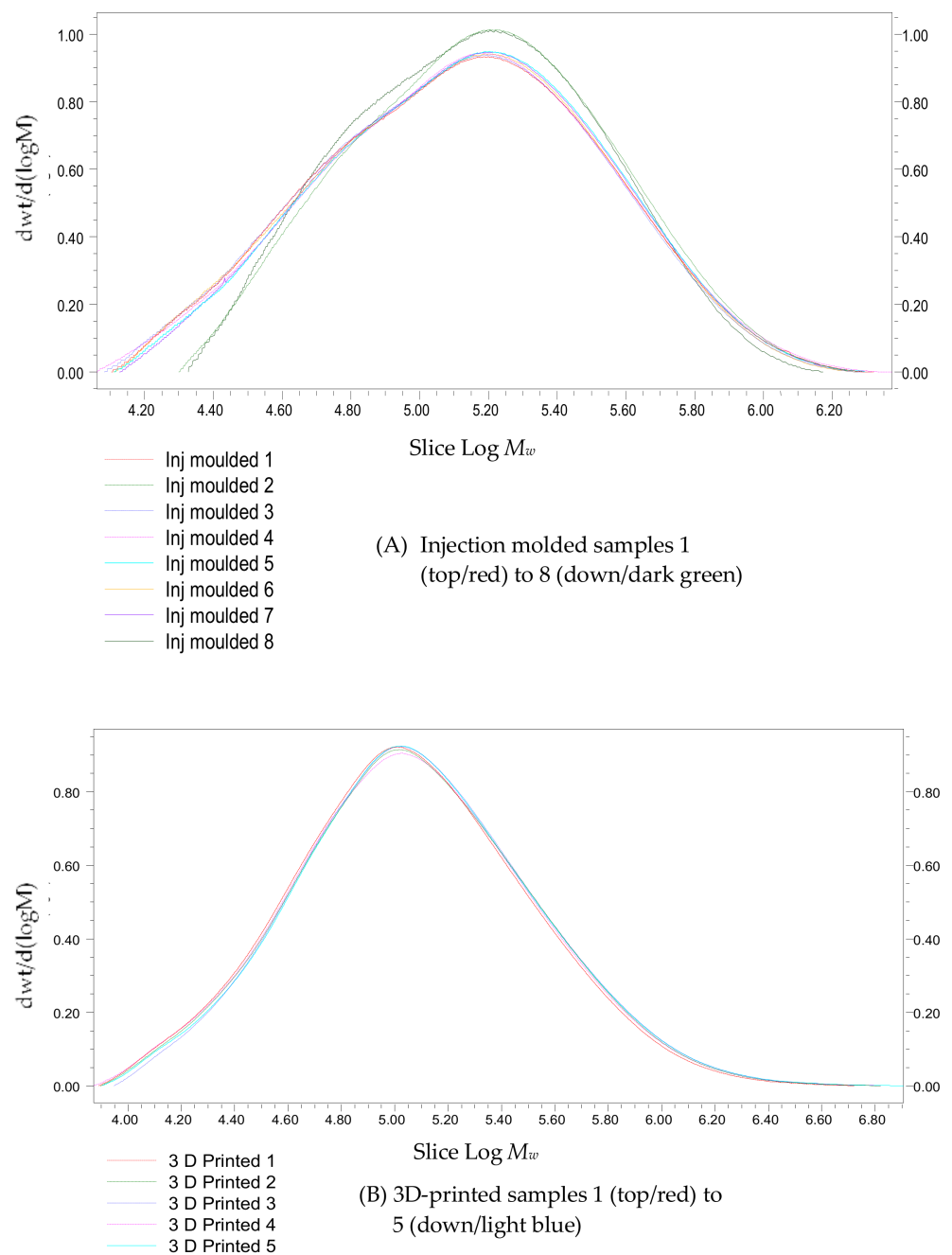

Figure 7. Molar mass distributions of the CAP polymer matrixes against PS standards for injection molded (A) and 3D printed (B) samples in chloroform.

Table 3. Results from particle size analysis for microcellulose particles separated from injection molded and 3D printed samples.

\begin{tabular}{cccc}
\hline \multirow{2}{*}{ Sample } & $\begin{array}{c}\mathbf{1 0 \%} \text { of Particles Below, } \\
\boldsymbol{\mu m}\end{array}$ & $\begin{array}{c}\mathbf{5 0 \%} \text { of Particles Below, } \\
\boldsymbol{\mu m}\end{array}$ & $\begin{array}{c}\mathbf{9 0 \%} \text { of Particles Below, } \\
\boldsymbol{\mu m}\end{array}$ \\
\hline IM-1 & 5.2 & 21.0 & 114 \\
IM-8 & 4.1 & 12.0 & 113 \\
3D-5 & 4.7 & 16.3 & 106 \\
\hline
\end{tabular}

\subsection{Mechanical Testing}

The results from mechanical testing are presented in Table 4 . Tensile strength and Charpy impact strength results are also displayed in Figures 8 and 9, respectively. The main finding is the strength level difference between injection molded and 3D printed materials. Weaker mechanical properties were observed in the 3D printed samples compared to the injection molded samples due to the more porous macrostructure and gaps between the printed layers from imperfect fusing (see SEM images in Figure 4 and microtomography images in Figure 5). These factors affect both tensile strength and Charpy impact strength properties and are discussed in more detail later in the discussion section. Tensile strength increased gradually with recycling for the injection molded samples most likely because of improved dispersion of fibers and/or their smaller size as a function of recycling. These 
effects can also be seen in the increased melt flowing properties (see Section 3.2.1) which provides evidence of increasing sample homogeneity with recycling and should lead to improved strength properties.

Table 4. Results from mechanical tests for recycled injection molded (IM) and 3D printed (3D) samples.

\begin{tabular}{ccccc}
\hline Sample & $\begin{array}{c}\text { Tensile Strength (at Yield) } \\
\mathbf{M P a}\end{array}$ & $\begin{array}{c}\text { Tensile Modulus } \\
\mathbf{M P a}\end{array}$ & $\begin{array}{c}\text { Strain at Break } \\
\mathbf{\%}\end{array}$ & $\begin{array}{c}\text { Charpy Impact Strength } \\
\mathbf{k J} / \mathbf{m} \mathbf{2}^{\mathbf{2}}\end{array}$ \\
\hline 1-IM & $25.5 \pm 0.1$ & $1841 \pm 69$ & $9.5 \pm 1.8$ & $21 \pm 2.7$ \\
2-IM & $26.5 \pm 0.2$ & $1735 \pm 47$ & $12.7 \pm 1.3$ & $25 \pm 4.8$ \\
3-IM & $26.6 \pm 0.2$ & $1712 \pm 53$ & $9.5 \pm 1.2$ & $20 \pm 2.8$ \\
4-IM & $27.3 \pm 0.1$ & $1778 \pm 62$ & $11.8 \pm 0.8$ & $22 \pm 5.1$ \\
5-IM & $27.4 \pm 0.2$ & $1777 \pm 62$ & $10.8 \pm 1.9$ & $24 \pm 4.0$ \\
6-IM & $27.6 \pm 0.2$ & $1731 \pm 14$ & $12.9 \pm 1.7$ & $27 \pm 5.4$ \\
7-IM & $27.9 \pm 0.1$ & $1789 \pm 38$ & $13.8 \pm 2.6$ & $27 \pm 6.4$ \\
8-IM & $28.0 \pm 0.2$ & $1856 \pm 112$ & $13.5 \pm 2.7$ & $26 \pm 7.3$ \\
1-3D & $11.6 \pm 0.4$ & $828 \pm 36$ & $3.2 \pm 0.4$ & $7.0 \pm 0.7$ \\
2-3D & $10.5 \pm 0.6$ & $716 \pm 30$ & $2.0 \pm 0.2$ & $6.0 \pm 0.5$ \\
3-3D & $13.5 \pm 0.3$ & $949 \pm 48$ & $2.9 \pm 0.8$ & $7.6 \pm 1.0$ \\
4-3D & $13.4 \pm 0.4$ & $962 \pm 45$ & $2.4 \pm 0.8$ & $7.0 \pm 1.0$ \\
5-3D & $13.3 \pm 0.4$ & $851 \pm 40$ & $3.3 \pm 1.1$ & $7.3 \pm 0.6$ \\
\hline
\end{tabular}

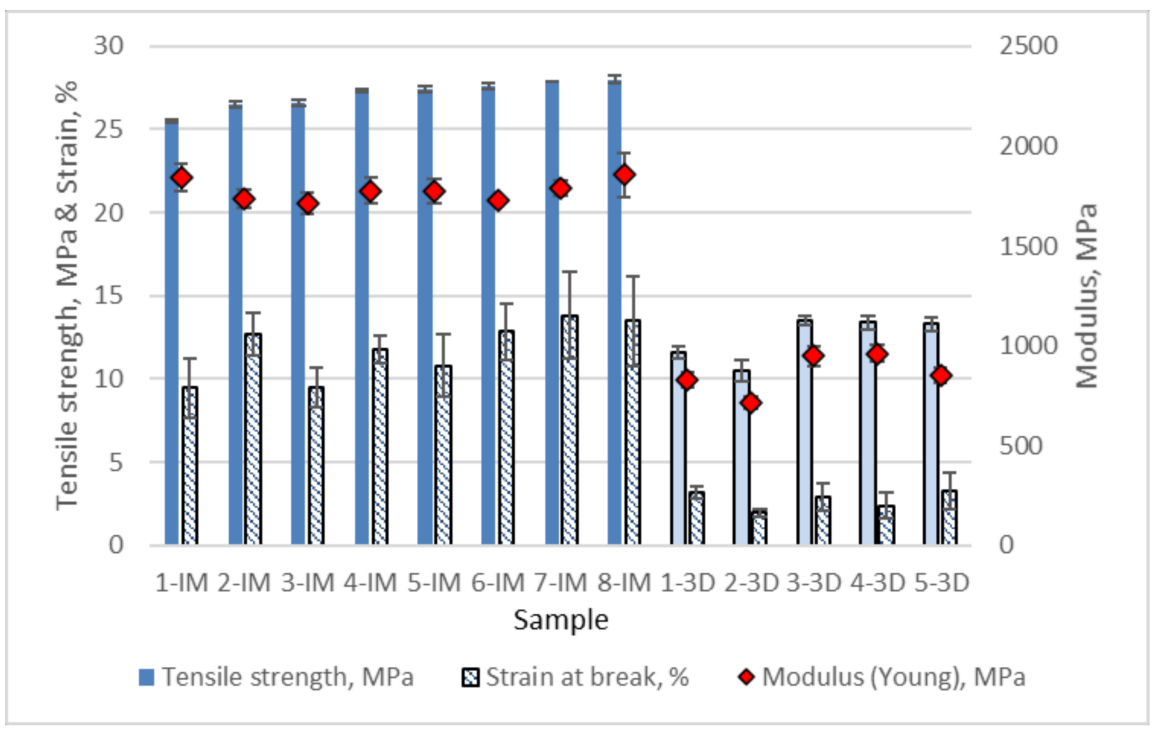

Figure 8. Results from tensile strength test for recycled injection molded (IM) and 3D printed (3D) materials.

\subsection{HDT}

The effect of recycling rounds and manufacturing processes on thermal behavior was analyzed by HDT and the results are presented in Figure 10. HDT results show how the higher porosity affects sample distortion under load for 3D printed samples, i.e., when the porosity decreases and the fusion of printed layers is enhanced after multiple recycling cycles, the HDT value increases. The effect of improved fiber dispersion can also be seen in the injection molded samples by a slightly increased HDT value from 62.2 to the max $64.4{ }^{\circ} \mathrm{C}$ of the material recycled three times (4-IM). 


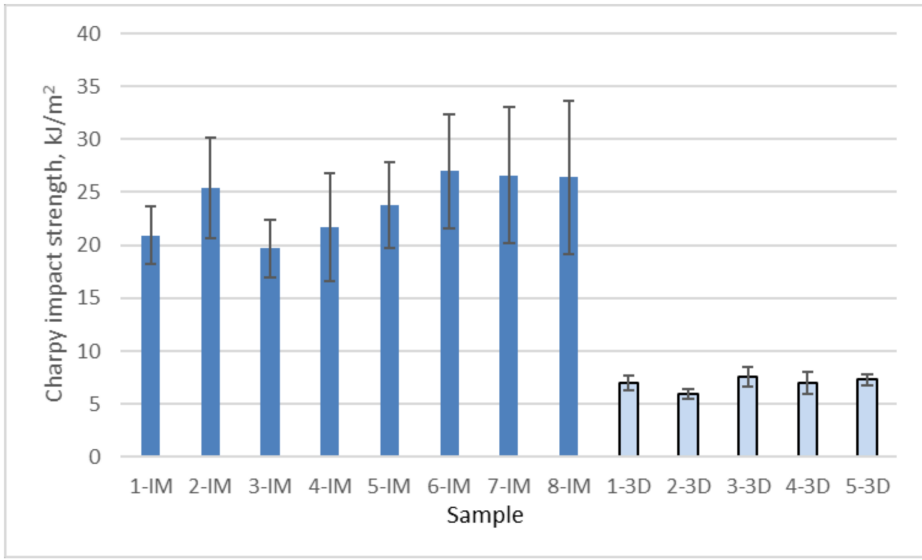

Figure 9. Charpy impact strength test results (unnotched) for recycled injection molded (IM) and 3D printed (3D) materials.

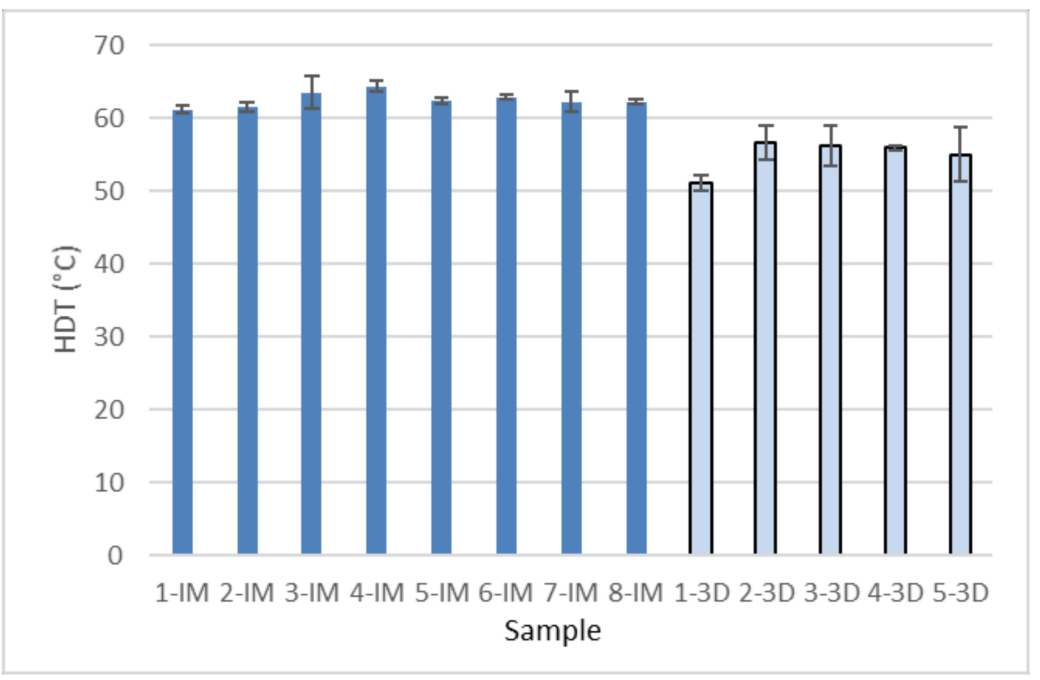

Figure 10. HDT results for the recycled injection molded and recycled 3D printed samples.

\section{Discussion}

A compound containing cellulose acetate propionate (CAP) with 13\% commercial plasticizer, microcellulose (MC) and epoxy-modified linseed oil as a coupling agent was prepared and processed by injection molding and granule 3D printing to test standard samples. The material was recycled seven times through the injection molding process and four times through the 3D printing process with only material grinding using a knife mill type granulator between the process steps. In thermoplastic material recycling, the use of a grinding process between recycling process steps is commonly used in injection molding and extrusion. This study showed that the examined materials can be used directly in a Brinter granular 3D printing process straight after grinding without a compounding stage. This indicates that one process step in material recycling can be eliminated compared to the recycling process typically used for thermoplastic 3D printed materials [8]. Eliminating the compounding process enables more cost-efficient and simpler use of material. Potentially, thermoplastic material 3D printing using granules instead of filaments can open novel and more flexible ways to work in distributed additive manufacturing.

The visual inspection of recycled compounds (see Figure 2) showed a gradual color change or darkening of the samples over multiple recycling process rounds. This observation is related to increased thermal stress effects mainly in the microcellulose fibers. As stated previously, the degradation of this material starts more intensively after $277{ }^{\circ} \mathrm{C}$ (TGA result for $5 \%$ degradation), but some degradation has already taken place at lower 
temperatures [24] with hemicellulose residues in microcellulose typically starting to degrade already at $200{ }^{\circ} \mathrm{C}$ [27]. Particle size analysis (see Table 3) showed reduction of microcellulose particle size with recycling for both the injection molding and 3D printing process. The size reduction is stronger in the injection molded material probably due to the more severe shear forces and higher pressuresused in the process during injection. The 3D printing process is comparable to extrusion processes or compounding, where less fiber cutting is directed on the material during the processing than in injection molding [28]. The size reduction of microcellulose is also evident in SEM-micrographs (Figures 3 and 4). SEM-micrographs for the injection molded materials 1-IM, 5-IM, and 8-IM in Figure 3 showed increasing homogeneity of the material, which is an indication of better fiber polymer coupling as a function of increased recycling process steps. In the 3D printed samples in Figure 4, the fibers remain rather large even after four recycling rounds (sample 5-3D). SEM-micrographs for the 3D printed samples also show the layer interface and increased fusion between the printed layers. The decrease in the void size was observed and validated by microtomography pictures in Figure 5. This enhanced layer adhesion and reduced number of voids is related to the lower viscosity of recycled materials and is confirmed by increased MFI as a function of recycling process steps. In materials with lower viscosity or higher MFI the leveling of printed material becomes easier, but also the void formation is reduced. The MFI was measured at $210{ }^{\circ} \mathrm{C}$, which was a compromise between the injection molding processing temperature of $200^{\circ} \mathrm{C}$ and the $3 \mathrm{D}$ printing temperature of $215^{\circ} \mathrm{C}$. MFI increased from the level of $5 \mathrm{~g} / 10 \mathrm{~min}$ to $18 \mathrm{~g} / 10 \mathrm{~min}$ during recycling. Compared to PLA materials used commercially in 3D printing, it can be seen that the MFI for materials before recycling and in the first recycled material is at the same level between 5 and $10 \mathrm{~g} / 10 \mathrm{~min}[29,30]$. Wang et al., 2017 measured the MFI of seven commercial PLA grades for 3D-printing, compared the results with 3D printing quality and concluded that a threshold MFI value of $10 \mathrm{~g} / 10 \mathrm{~min}$ for an MFI predicts good flowability and layer adhesion and enables a fast screening of PLA materials for 3D printing. The authors also noted that in addition to the MFI value, both the plasticizer type and crystallinity influence the printing result [31]. Initially, the material MFI is within the typical limit for injection moldable material, but with recycling, the MFI increases and the material becomes more easily injection moldable as the MFI is already over $10 \mathrm{~g} / 10 \mathrm{~min}$ after five injection molding cycles [32].

Molar mass, which is related to material viscosity, was analyzed and the results are presented in Table 2 and Figure 7. It was found that the weight average molar mass, $M_{w}$, stays at the same level of 205,000 $\pm 80001 / \mathrm{mol}$ for both the injection molded and 3D printed samples and does not show any clear changes with recycling. These results confirm that the polymer matrix is not degraded during recycling. However, there is a significant difference in $M_{n}$ and $Ð$ between the injection molded and 3D printed samples. $M_{n}$ is the average molar mass of individual molecules and as such the number of different chain lengths is more significant than for $M_{w}$ as smaller molecules have more representative influence. The chromatographs in Figure 7 reveal the presence of smaller molecules in the $3 \mathrm{D}$ printed polymer matrixes than in the injection molded polymer matrixes. The presence of smaller molecules is reflected also as wider polymer size distribution and higher value in dispersity, $\oslash$ for, 3D printed polymers compared to those that were injection molded, 2.8-2.9 vs. 1.9-2.3, respectively. One explanation is that the reactive additive, epoxidized linseed oil, has acted more efficiently as a coupling agent between polymer chains during injection molding due to higher pressures and shear forces in processing than in 3D printing, which reduces the number of smaller molecules during injection molding. Another explanation could be the higher processing temperature in $3 \mathrm{D}$ printing $\left(215^{\circ} \mathrm{C}\right)$ compared to injection molding $\left(200^{\circ} \mathrm{C}\right)$. A higher processing temperature could favor polymer chain scission during the numerous processing steps even though the used polymer has a recommended processing temperature of up to $230^{\circ} \mathrm{C}$. This possibility should be confirmed by FTIRanalysis. However, the MFIs presented here confirm the higher flow properties of materials 
recycled via the 3D printing route which is good indication of the presence of shorter polymer chains.

The results for mechanical properties in Table 4 and Figures 8 and 9 show the strength level difference between the injection molded and 3D printed materials. The tensile strength and modulus values of $3 \mathrm{D}$ printed materials are less than $50 \%$ of the injection molded materials and Charpy impact strength is less than $30 \%$ which is in line with results measured from PLA wood fiber composite samples by Zandi et al., 2020 [33]. Xiao et al., 2019 compared the mechanical properties of 3D printed and injection molded hemp hurd $(\mathrm{HH})$ PLA/PBAT (polybutylene adipate-co-terephtalate) composites with varying $\mathrm{HH}$ loading and concluded that with high $\mathrm{HH}$ loading the tensile strength decreased approximately $60 \%$ with $3 \mathrm{D}$ printed specimens and impact strength decreased approximately $10 \%$ compared to injection molded specimens. The good impact properties were highly affected by a toughening and compatibilization agent used in the compounds [34]. The tensile strength was 25.5 to $28 \mathrm{MPa}$ in the injection molded materials and 10.3 to $13.5 \mathrm{MPa}$ in the 3D printed materials. The modulus difference in the injection molded and the 3D printed samples is from 1712-1856 to $716-962 \mathrm{MPa}$, respectively, and Charpy impact strength is from $20-27$ to $6.0-7.6 \mathrm{~kJ} / \mathrm{m}^{2}$, respectively. This level of difference comes from the more porous macrostructure and gaps between the printed layers, imperfectly fused together, in the $3 \mathrm{D}$ printed materials. The mechanical properties of the $3 \mathrm{D}$ printed samples were slightly improved after the second recycling round which at least partly is a result of a changed 3D printing strategy, i.e., the number of layers in the $3 \mathrm{D}$ printed specimens was 5 in the first two rounds and 7 in the rest of the rounds. In addition, the layer height was reduced from 0.8 to $0.5 \mathrm{~mm}$ in the last three rounds. The other 3D printing parameters were kept constant. Rimašauskas et al. studied the effect of 3D printing parameters on 3D printing quality and concluded that pore volume decreased and the tensile strength increased by reducing the layer thickness of 3D printed parts [35]. Similar conclusions were made by Rajpurohit and Dave in which the lower layer height of PLA specimens was observed to enhance tensile strength because of higher bonding area between the layers [36]. In injection molded materials the tensile strength increases gradually with recycling, most likely because of the improved dispersion of microcellulose fibers and their smaller size. There is also an indication of increased Charpy impact strength in the recycled injection molded materials. This result, together with the relatively good polymer matrix stability, demonstrates the good recycling potential of cellulose ester-based microcellulose composites.

The thermal stability of injection molded and 3D printed materials during recycling was analyzed using HDT. The results presented in Figure 10 show a level difference of $15-20 \%$ between the injection molded and 3D printed samples. This is probably due to the higher porosity of the 3D printed samples, which influences the sample distortion under load, leading to lower values. When the porosity decreases and the fusion of printed layers is enhanced after multiple recycling cycles, the HDT value increases to a maximum of $56.7^{\circ} \mathrm{C}$. The effect of improved fiber dispersion can also be seen in the injection molded samples by the slight increase in the HDT value from 62.2 to a max of $64.4{ }^{\circ} \mathrm{C}$ after the material is recycled three times (4-IM). The higher $\mathrm{Mn}$ value in the injection molded materials may also have some small effect on the higher HDT value.

\section{Conclusions}

This study showed that a novel granular 3D printing method enables thermoplastic material recycling to go back to the printing process straight after material grinding without a compounding stage, thus potentially saving costs and energy, and minimizing waste in processing. The studied thermoplastic cellulose acetate propionate compound containing microcellulose retained its mechanical and thermal properties up to seven recycling process cycles for injection molding, and at least four recycling process cycles for the granular $3 \mathrm{D}$ printing process. In the $3 \mathrm{D}$ printing process, printability was improved by increasing recycling rounds due to increasing MFI, which enabled better layer adhesion and reduced porosity in the material. The main challenge was maintaining the original color of the com- 
pound due to microcellulose degradation with increasing thermal stress, even though the improved microcellulose dispersion and fiber size cutting improved material performance. According to these results, the optimal recycling amount without adding virgin material in the process could be four to five times more for this material compound. Overall, the findings reported in this paper indicate that modified celluloses have further potential to enable sustainable 3D printing, but further developments are required in materials science before all of that potential can be realized.

Author Contributions: Writing-original draft preparation, K.I.; writing-review and editing, S.M.-K.; writing, J.N.; writing and SEM analytics, A.T.; writing and SEC analytics, A.M.; writing and microtomography, T.T.; supervision, O.-V.K.; supervision of 3D-printing, T.K.; review and project administration, H.K. All authors have read and agreed to the published version of the manuscript.

Funding: This research was funded by the EU-project NOVUM, grant number 768604 .

Institutional Review Board Statement: Not applicable.

Informed Consent Statement: Not applicable.

Data Availability Statement: The data are available from the authors.

Acknowledgments: The authors would like to thank Sini-Tuuli Rauta, Petri Kuusipalo, Olli Linjamaa and Hanna-Mari Sinilehto for material processing and contribution in sample analytics, and Pia Willberg-Keyriläinen for cellulose ester C16 preparation. Lari Nieminen from Brinter is acknowledged for performing printing trials and Timothy Schatz for language corrections.

Conflicts of Interest: The authors declare no conflict of interest.

\section{References}

1. Statista. Additive Manufacturing \& 3D Printing Worldwide ID 755074; Statista: Hamburg, Germany, 2021.

2. BCC Research. Global Markets for 3D Printing, Copyrighted Material, All Rights Reserved; BCC Research: Wellesley, MA, USA, 2021.

3. Kellens, K.; Baumers, M.; Gutowski, T.G.; Flanagan, W.; Lifset, R.; Duflou, J.R. Environmental Dimensions of Additive Manufacturing: Mapping Application Domains and Their Environmental Implications. J. Ind. Ecol. 2017, 21, S49-S68. [CrossRef]

4. Mikula, K.; Skrzypczak, D.; Izydorczyk, G.; Warchoł, J.; Moustakas, K.; Chojnacka, K.; Witek-Krowiak, A. 3D printing filament as a second life of waste plastics-A review. Environ. Sci. Pollut. Res. 2020, 28, 12321-12333. [CrossRef] [PubMed]

5. Mohan, D.; Teong, Z.K.; Bakir, A.N.; Sajab, M.S.; Kaco, H. Extending cellulose-based polymers application in additive manufacturing technology: A review of recent approaches. Polymers 2020, 12, 1876. [CrossRef] [PubMed]

6. Mervine, N.; Brätt, K.; Saloni, D. A Review of Sustainable Materials Used in Thermoplastic Extrusion and Powder Bed Melting Additive Manufacturing. In Advances in Intelligent Systems and Computing, Proceedings of the International Conference on Applied Human Factors and Ergonomics, New York, NY, USA, 24-28 July 2022; Springer: Cham, Switzerland, 2020; Volume 1216 AISC, pp. 95-102.

7. Jawahir, I.S.; Bradley, R. Technological Elements of Circular Economy and the Principles of 6R-Based Closed-loop Material Flow in Sustainable Manufacturing. Procedia CIRP 2016, 40, 103-108. [CrossRef]

8. Association of Plastic Recyclers. Life Cycle Impacts For Postconsumer Recycled Resins: PET, HDPE, AND PP; Franklin Associates, A Division of ERG: Washington, DC, USA, 2018. Available online: https:/ / plasticsrecycling.org/images/library/2018-APR-LCIreport.pdf (accessed on 16 December 2021).

9. Cruz Sanchez, F.A.; Boudaoud, H.; Camargo, M.; Pearce, J.M. Plastic recycling in additive manufacturing: A systematic literature review and opportunities for the circular economy. J. Clean. Prod. 2020, 264, 121602. [CrossRef]

10. Cress, A.K.; Huynh, J.; Anderson, E.H.; O'neill, R.; Schneider, Y.; Keleş, Ö. Effect of recycling on the mechanical behavior and structure of additively manufactured acrylonitrile butadiene styrene (ABS). J. Clean. Prod. 2021, 279, 123689. [CrossRef]

11. Vidakis, N.; Petousis, M.; Tzounis, L.; Grammatikos, S.A.; Porfyrakis, E.; Maniadi, A.; Mountakis, N. Sustainable additive manufacturing: Mechanical response of polyethylene terephthalate glycol over multiple recycling processes. Materials 2021, 14, 1162. [CrossRef] [PubMed]

12. Vidakis, N.; Petousis, M.; Tzounis, L.; Maniadi, A.; Velidakis, E.; Mountakis, N.; Kechagias, J.D. Sustainable additive manufacturing: Mechanical response of polyamide 12 over multiple recycling processes. Materials 2021, 14, 466. [CrossRef] [PubMed]

13. Vidakis, N.; Petousis, M.; Tzounis, L.; Maniadi, A.; Velidakis, E.; Mountakis, N.; Papageorgiou, D.; Liebscher, M.; Mechtcherine, V. Sustainable additive manufacturing: Mechanical response of polypropylene over multiple recycling processes. Sustainability 2021, 13, 159. [CrossRef]

14. Spoerk, M.; Arbeiter, F.; Raguž, I.; Holzer, C.; Gonzalez-Gutierrez, J. Mechanical Recyclability of Polypropylene Composites Produced by Material Extrusion-Based Additive Manufacturing. Polymers 2019, 11, 1318. [CrossRef] 
15. Cruz Sanchez, F.A.; Boudaoud, H.; Hoppe, S.; Camargo, M. Polymer recycling in an open-source additive manufacturing context: Mechanical issues. Addit. Manuf. 2017, 17, 87-105. [CrossRef]

16. Fazita, M.R.N.; Jayaraman, K.; Bhattacharyya, D.; Hossain, M.S.; Haafiz, M.K.M.; Abdul Khalil, H.P.S. Disposal Options of Bamboo Fabric-Reinforced Poly(Lactic) Acid Composites for Sustainable Packaging: Biodegradability and Recyclability. Polymers 2015, 7, 1476-1496. [CrossRef]

17. Chaitanya, S.; Singh, I.; Song, J. Il Recyclability analysis of PLA/Sisal fiber biocomposites. Compos. Part B Eng. 2019, 173, 106895. [CrossRef]

18. Åkesson, D.; Fazelinejad, S.; Skrifvars, V.V.; Skrifvars, M. Mechanical recycling of polylactic acid composites reinforced with wood fibres by multiple extrusion and hydrothermal ageing. J. Reinf. Plast. Compos. 2016, 35, 1248-1259. [CrossRef]

19. Properties and Applications of Cellulose Propionate (CP). Available online: https: / www.azom.com/article.aspx?ArticleID=389 (accessed on 16 December 2021).

20. CELLULOSIC PLASTICS. Available online: https:/ / powerplasticrecycling.com/cellulosic-plastics/ (accessed on 16 December 2021).

21. Hunt, E.J.; Zhang, C.; Anzalone, N.; Pearce, J.M. Polymer recycling codes for distributed manufacturing with 3-D printers. Resour. Conserv. Recycl. 2015, 97, 24-30. [CrossRef]

22. Recycling Codes. Available online: https://en.wikipedia.org/wiki/Recycling_codes (accessed on 16 December 2021).

23. Mohanty, A.K.; Wibowo, A.; Misra, M.; Drzal, L.T. Development of renewable resource-based cellulose acetate bioplastic: Effect of process engineering on the performance of cellulosic plastics. Polym. Eng. Sci. 2003, 43, 1151-1161. [CrossRef]

24. Immonen, K.; Willberg-Keyriläinen, P.; Ropponen, J.; Nurmela, A.; Metsä-Kortelainen, S.; Kaukoniemi, O.V.; Kangas, H. Thermoplastic Cellulose-Based Compound for Additive Manufacturing. Molecules 2021, 26, 1701. [CrossRef]

25. Albis Plastics GmbH Material Data Center Datasheet for Cellidor CP300-13. Available online: https://www.materialdatacenter $\mathrm{com} / \mathrm{ms} / \mathrm{en} /$ Cellidor/ALBIS+PLASTIC+GmbH/10 (accessed on 16 December 2021).

26. Willberg-Keyriläinen, P.; Talja, R.; Asikainen, S.; Harlin, A.; Ropponen, J. The effect of cellulose molar mass on the properties of palmitate esters. Carbohydr. Polym. 2016, 151, 988-995. [CrossRef]

27. Vanhatalo, K.; Maximova, N.; Perander, A.M.; Johansson, L.S.; Haimi, E.; Dahl, O. Comparison of conventional and lignin-rich microcrystalline cellulose. BioResources 2016, 11, 4037-4054. [CrossRef]

28. Virtanen, S.; Wikström, L.; Immonen, K.; Anttila, U.; Retulainen, E.; Virtanen, S.; Wikström, L.; Immonen, K.; Anttila, U.; Retulainen, E. Cellulose kraft pulp reinforced polylactic acid (PLA) composites: Effect of fibre moisture content. AIMS Mater. Sci. 2016, 3, 756-769. [CrossRef]

29. Innofil PLA by Innofil3D, BV. Available online: https:/ /www.3d-tulostus.fi/WebRoot/vilkas04/Shops/20131018-11092-2648461/5C8B/826C/D5D6/09A3/AD95/0A28/1011/7CA4/TDS_EN_Innofil3D_PLA.pdf (accessed on 22 December 2021).

30. Ultimaker Technical Data Sheet PLA. Available online: https://support.ultimaker.com/hc/en-us/articles/360011962720 (accessed on 22 December 2021).

31. Wang, S.; Capoen, L.; D'hooge, D.R.; Cardon, L. Can the melt flow index be used to predict the success of fused deposition modelling of commercial poly(lactic acid) filaments into 3D printed materials? Plast. Rubber Compos. 2017, 47, 9-16. [CrossRef]

32. Sepe, M. Melt Flow Rate Testing_Part 1 Plastics Technology. Available online: https://www.ptonline.com/articles/melt-flowrate-testingpart-1 (accessed on 22 December 2021).

33. Zandi, M.D.; Jerez-Mesa, R.; Lluma-Fuentes, J.; Jorba-Peiro, J.; Travieso-Rodriguez, J.A. Study of the manufacturing process effects of fused filament fabrication and injection molding on tensile properties of composite PLA-wood parts. Int. J. Adv. Manuf. Technol. 2020, 108, 1725-1735. [CrossRef]

34. Xiao, X.; Chevali, V.S.; Song, P.; He, D.; Wang, H. Polylactide/hemp hurd biocomposite as sustainable 3D printing feedstock Compos. Sci. Technol. 2019, 184, 107887. [CrossRef]

35. Rimašauskas, M.; Jasiūnienè, E.; Kuncius, T.; Rimašauskienė, R.; Cicènas, V. Investigation of influence of printing parameters on the quality of 3D printed composite structures. Compos. Struct. 2022, 281, 115061. [CrossRef]

36. Rajpurohit, S.R.; Dave, H.K. Effect of process parameters on tensile strength of FDM printed PLA part. Rapid Prototyp. J. 2018, 24, 1317-1324. [CrossRef] 